\title{
Nurturing Children's Health Through Neighbourhood Morphology
}

Priya R Khatavkar

K S School of Architecture, Bengaluru, Karnataka, India

Email: priyark@kssa.edu.in

\section{ARTICLE INFORMATION}

Received: February15, 2018

Revised: May 22, 2018

Accepted: June 18, 2018

Published online: July 02, 2018

\section{Keywords}

Children's outdoor activities; Independent Mobility; Spatial planning; Sustainable play spaces; Child Friendly route.

\section{ABSTRACT}

Among the key factors required for the adequate development and growth of children's physical and mental health is the child's outdoor activities. Master plans are inclusive and provide sustainable settlements when they accommodate and respond to children. An understanding of the child's need for outdoor spaces will help build better public spaces thereby providing opportunities for better physical, mental and emotional health of children. This paper is an effort to explore those environmental settings which are conducive for their physical activities. It tries to uncover the spatial planning approach which can contribute to child friendly spaces. The study is an investigation and a comparative analysis of a planned and an organic settlement in an urban fabric; HSR layout and Mangammanapalya in Bangalore, India. A qualitative analysis of the various layers of the physical settings has been done. The investigations reveal how each settlement caters to and supports the physical needs of children. The goal is to make use of these findings in the future planning and design intervention of neighbourhoods. The findings for the planned settlement, HSR revealed the presence of amenities like parks, playgrounds and sports facilities which the children frequented. The organic settlement lacked the presence of parks but the street network pattern revealed a majority of dead ends which are used as play spaces by children. Increase in commercial use in the settlement of HSR brought about the threat of traffic and stranger danger which act as deterrents to the independent mobility of the child while Mangammanapalya because of its cul de sacs which discourage through traffic offered a relatively safe and sustainable environment for play and mobility on its streets. A child friendly route could act as a safe and interesting path for children to explore the neighbourhood.

\section{Introduction}

Having ratified the Convention of Rights of Child (CRC) with the UN, India is committed to promoting the well being and the rights of the child. The CRC recognizes a child as under 18 years of age. It also recognizes the need for the child's right to rest and leisure, to engage in play and recreational activities and to participate freely in cultural life and the arts. This becomes important to improve the quality of life in all spheres including urban planning. India stands second in the world by population, the first being China. By approximately seven years, the population of India is estimated to be more than that of China (Esa.un.org, 2018). India houses the largest child and youth population in the world. With a fertility rate of 2.3, India is ensured of the largest youthful population in the world for the coming decade ahead (mospi.nic.in, 2017). Therefore it becomes all the more important for the Government to invest in the youth. In India, Bangalore is one of the fastest growing metropolitan cities. With its population of 8.4 million it is one of the largest urban centers in the country (censusindia. gov.in, 2011). Moreover the population projection of
Bangalore for 2031 is likely to increase more than two fold to 20.3 million (data.opencity.in, 2018).

Given this kind of a fast pace of urbanization in India, physical environments with settings which fulfills the mental and physical development needs of children are challenged. Urbanization has devoured open spaces which are crucial for children's outdoor activities. With an increase in urbanization, children's freedom to roam and explore has been decreasing (Islam, 2008). Children's outdoor activity has been profoundly affected by drastic changes in contemporary urban outdoors not only by population but also by other related factors such as density and traffic (Islam, 2008). This crunch in space for outdoor activities is a current issue which is detrimental to the child's physical and mental health. Outdoor facilities are being replaced by indoor provision of technologically advanced play equipments. Not spending time outdoors, children take up home based activities indoors, resulting in a sedentary lifestyle. This being one of the reasons children's health is at risk to diseases like overweight and obesity (Galson, 2008). 


\subsection{Aim, Scope and Limitations}

The physical environment of a neighborhood exerts a strong influence on the outdoor activities of a child. Affordances in an environmental setting can influence the mobility of children. Multiple affordances promote various activities accommodating a child to move around freely in a structured or unstructured way including play. The aim of the study is to explore how the built environment variables support children's activities. The scope includes the physical settings which aid the mobility of the child within the neighbourhood including those which support active play. The study focuses on populations residing in a residential or mixed use neighbourhood in an urban environment. Therefore the findings may be limited to similar population groups and may not be true for other types of populations.

\section{Defining Participants in the Study}

\subsection{Middle Childhood}

Middle childhood from the age of 7 to 12 years is a period of relative independence, socialisation and exploration. This is also the age of independent mobility and freedom in children (Islam, 2008). It is during this time that children start developing social relationships and learn life skills that help them develop into healthy adolescents. Children in their middle childhood actively use outdoor space. They are more likely to use parks, play grounds and streets as play areas. They can think logically, reason and solve a variety of problems. Middle childhood is an important time for developing the self concept and one's personality.

\section{The Need for Outdoor Activities and its Benefits}

Through outdoor physical activities developmental needs are fulfilled in Children. Playing activities play an important part in the healthy physical, emotional and mental development of a child. The benefits include physical strength, agility, flexibility, smooth and strong motor skills, developing decision making, problem solving, social and emotional skills. Organised or unorganised physical activity is essential for children to maintain an energy balance, cardiovascular development, endurance, balance and physical tolerance (Kristin, T., 2008). Children's free play is enjoyable, free of adult intervention, lively, imaginative, non-goal oriented, impulsive, active, vibrant, child driven and is vital for healthy development. Children learn through play the various aspects of communication, developing and maintaining social relationships and how to deal with people and time (Kristin, T., 2008). Engaging with nature has become a challenge in today's urban world.
As much as the rural environments offer the experience of binding with nature and learning from a natural habitat, it is quite improbable that an urban area would possess such environments. Playing in a natural territory has its own benefits. Children learn what they cannot be taught. Activities like climbing trees and making dens can result in mental well being and self esteem.

\subsection{Threats to Children's Outdoor Activities and Parental Perception of Safety}

Traffic levels could hinder independent mobility and active play of the child. Environment behaviour research has identified traffic as one of the biggest threats to children's outdoor activity (Hanapi and Ahmad, 2016). Roads with heavy traffic volume and high traffic speeds act as boundaries. They become the limits of the child's perception of neighbourhood. When the neighbourhood experiences an increase in the non residential land use patterns, the threat of strangers are also likely to increase (Islam, 2008). The perception of stranger danger affects the extent to which the child explores and travels about in the neighbourhood. Parents perception of traffic, stranger and fear of injury also affects independent mobility of children. Parent's concern with regards to traffic safety has grown, whereby they do not freely permit outdoor play (Brussoni et al., 2018). Parents physical activity along with their perceptions of safety also have an influence on the independent mobility of children. Their interpretation and identification of the parameters regarding local road safety, presence of sidewalks, the number of accidents in the neighbourhood, absence of crossing facilities influence children's mobility (Santos et al., 2013). These in turn dictate limits of travel and exploration. Parents might feel that it is not safe for a child to cross a busy road by himself and prohibit him from doing it.

\section{Physical Settings that Facilitate Outdoor Activities}

The different environmental settings can be structured into a system of settings as it may not be approriate to consider them in isolation. This system of settings are preferred on the basis of environmental quality. The behaviour is linked to the system of settings through activities. Every element is loaded with signals and sends cues to the receiver. Through cognition, evaluation, perception and preference the receiver connects and responds to the environmental settings through his behaviour. The interpretation of the signals depends on the personal and cultural understanding of the recipient. The response through behaviour adds meaning to the environmental setting. Thus both the object and the person determine the affordances. (Kristin, T., 2008). 
The system of settings include accessibility of paths and routes that connect to the desired destination and the availability of spaces where play and sports can take place. Proximity to playgrounds provide opportunities to increase physical activities of children. Footpath and sidewalks, streetlights, traffic speed and volume, frequency and height of trees encourage and support outdoor activities. Availability of spaces like street corners, rooftops, alleys, vacant land, empty building plots offer informal spaces to play and socialise. Mixed land use and street connectivity could aid activities like walking and cycling. The study explores these settings and identifies those that are conducive for physical activities of children.

\section{Built Environment Variables}

There are links between various elements of the physical setting and children's outdoor activities. The study is an effort to improve the understanding of how individual attributes of the built environment affect the outdoor activities of children. A qualitative assessment of a few layers which seemed to have a strong impact on physical activities were taken up: 1) Land use and population density, 2) Open spaces, 2a) Typology of open spaces, 3) Street characteristics and Territoriality and 4) Street network pattern. These variables are part of immediate outdoor surroundings for the children in the neighbourhood and have a close relationship to outdoor activities.

\subsection{Land Use and Population Density}

If the settlement had only residential land use, then length between destinations would be greater, increasing trip distances and affecting parental apprehension and safety. Motorised means of travel might be the only effective ways to get around which discourages physical activities. Nonresidential land use in the neighbourhood could influence physical activity levels in children. Mixed land use along with higher population densities reduces distances to services, stores and friends. It has the potential to make transport more sustainable and encourages non-motorized means of travel in children. Benefits are accrued through economies of scale. It can aid in greater community cohesion, reducing parental concerns regarding safety and result in reduced distances to destinations (Waygood and Kitamura, 2009).

\subsection{Open Spaces}

It is acknowledged that open spaces do have an impact on children's outdoor activities and subsequently their health and well being. The quality of the urban environment influences the levels of physical activity and the quality of life. Availability and accessibility to high quality open and green spaces has a favourable effect on longevity of life, happiness, health and general wellbeing. This is reflected in the competence and capability of individuals and the whole society Thompson (2013). Open spaces have a positive effect on physical activities. Open spaces need to be culturally appropriate, readily accessible and well connected. Availability of informal public spaces, allow children to connect with natural environment.

\subsubsection{Typology of open spaces}

Different types of activities need different types of spaces. The different types of open spaces are park and playgrounds, urban green scapes like wetlands, lakes, wastelands etc, green corridors like canal banks, cycle ways, outdoor sports facilities like school playing fields, sports areas and amenity green spaces in housing colonies. All these spaces have immense scope for development. Varied environmental settings foster development and growth in children. These spaces vary in importance and mediate opportunities for healthy development and social relationships (Kristin, T., 2008). A number of type of spaces may contribute to the healthy physical and mental development of a child; spaces enclosed by apartments or colonies, the setback area in an independent plot, the cul de sac etc provide opportunities for interaction with other children, youth and adults serving as a mediator of social relationships and thereby fostering healthy development.

\subsection{Street Characteristics Inducing Territorial Space}

Outdoor settings have been severely restricted in urban spaces. During middle childhood the children explore the neighbourhood and look for spaces they can claim as their own. The home range or exploration range for a child could be affected by characteristics of the street such as width, types of vehicles that ply on it, volume of traffic it carries and traffic speeds. Territorial ranges could range from a residential block to the entire neighbourhood. Territorial model has been conceptualized as occasional, habitual and frequented (Islam, 2008). While the regular range can revolve around spaces pertaining to home, frequented range is influenced by busy roads, permission of parents and stranger danger. Occasionally visited boundary ranges are characterized by the third model. Territorial space is determined by edges, enclosures, landmarks etc and become important reference points. The quality of these affect the children's travel patterns and their freedom to explore the environment.

\subsection{Street Network Pattern}

Highly connected street network promote physical activities like walking and cycling to school provided there is low traffic. 
It is found that children located in areas where there the street connectivity is good, but with high levels of traffic do not walk to school (Giles-Corti et al., 2011). Access to walking destinations like shops, parks and playgrounds with a high level of permeability can support increased levels of physical activities. Connectivity, without imposing significant detours and allowing users to travel shorter distances while offering them a choice from the range of possible routes promote active travel network. Children tend to use the streets more for play in spite of the range of green and open spaces that have been provided because of its immediate availability and proximity to home. Street networks which promote reduction in motorized traffic levels and speeds increases one's perception of safety and security enhancing children's use of streets through walking, cycling and play. Cul-de-sacs are affordances that maximize opportunities for active and extended duration of play in a street network. Though play environment is to be viewed in totality, analyzing the physical settings individually would help build a better understanding of the effect of those elements contributing to the total picture. In a rapidly urbanizing scenario like Bangalore these layers take on a dynamic position as residential areas are constantly evolving and growing. It could be possible to direct this growth in a manner to enable better levels of physical activity and thereby better physical, emotional and mental health among children.

\section{Site Selection}

The study is a comparative analysis of the settings a planned settlement and an organic settlement can provide to encourage outdoor activities of children. The study areas are located in Bangalore, India. The Bengaluru Bruhat Municipal Palike (BBMP) map showing the percentage of 0 to 6 years age group population was considered. It was observed that the wards which had higher percentages of $12.1 \%$ and above of 0 to 6 years age population (Fig 1, represented in dark brown and red) ranged from the North to Northeast to South of Bangalore, along the IT corridor. These twenty wards are located just outside the Outer Ring road along the IT corridor where there are many growing residential developments. Out of these twenty wards, a planned layout with a moderate residential density i.e HSR layout and an organic settlement with a high residential density i.e Mangammanapalya was selected for the comparative analysis.

\subsection{The Study Areas}

Ward num174 is HSR (Hosur Sarjapur Road) layout, a planned layout in South Bangalore. HSR was developed by the BDA in 1985. It is ideally located between Hosur road and Sarjapur road in the IT corridor. Due to its proximity to the IT parks it has become a leading residential area through the

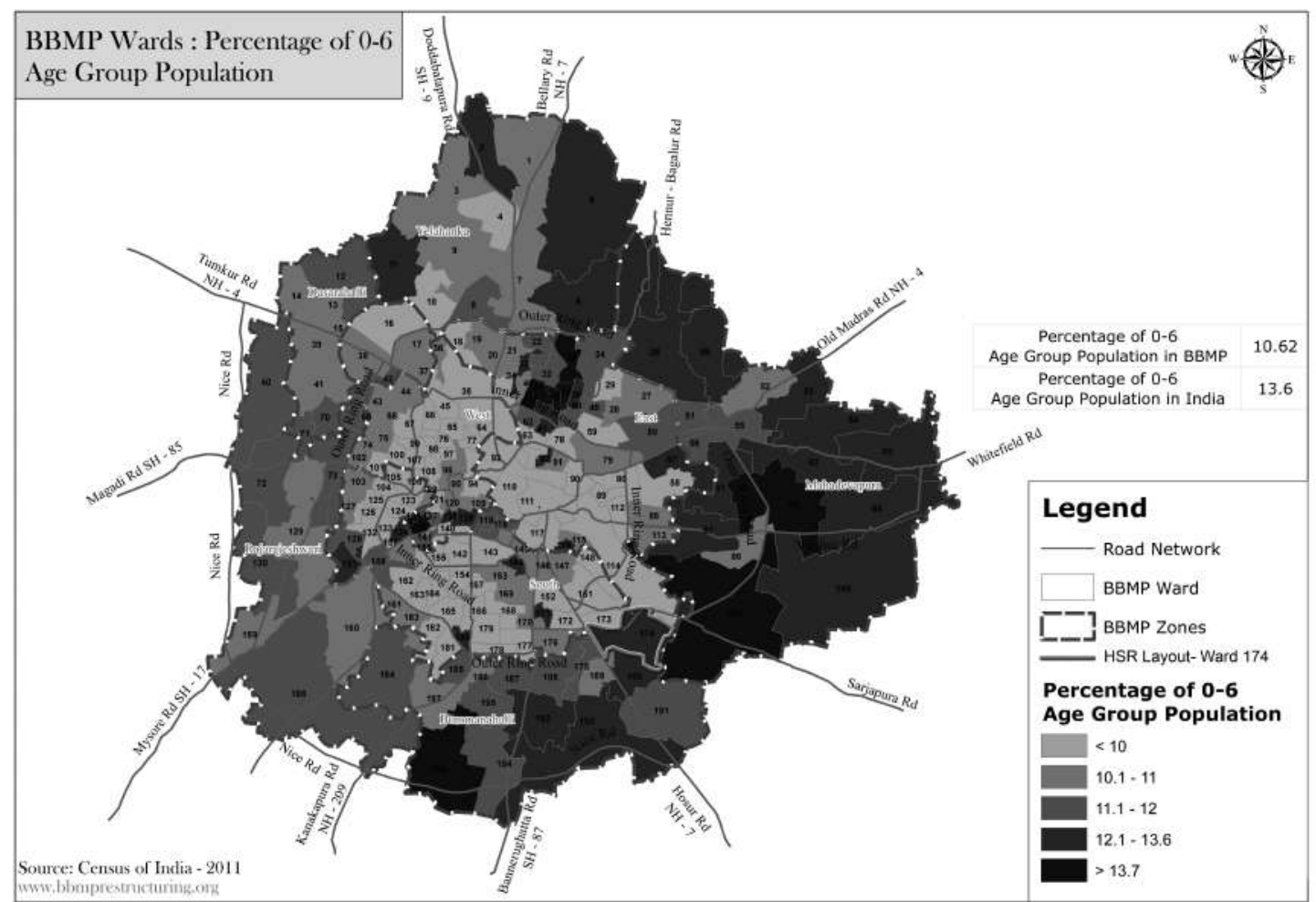

Figure 1. BBMP Ward Map showing percentage of 0 to 6 years age group population. (Source: Census, 2011) 
Outer ring road and Hosur road. Connectivity is supported by city level trunk services and feeder corridors HSR has a moderate gross density of 8,878 person per Sq. Km with a population of 63,033 persons and an area of 7.1 Sq.Km (Census, 2011). The study area is the 6th sector in HSR (Fig 2- denoted in bright red) which is bounded by Outer ring road on the Northern side, $14^{\text {th }}$ main road on the Eastern side, $17^{\text {th }}$ cross road on the southern side and Hosur road on the western end. Socio economically, HSR consists of a mixed household of walkup apartments and independent houses with a plot area of 1200 to 2400 square feet. Mangammanapalya - ward number 190 is adjacent to HSR and lies on its southern side. This ward has the highest gross density of 18,956 ( persons per Sq.Km) among all twenty wards with a population of 65,890 persons and an area of 3.5 sq.Km (Census 2011). The study area (refer Fig 2, denoted in bright yellow) is the locality with the same name as the ward name -Mangammanapalya. The area hosts a bus terminus with feeder corridors and is connected to city trunk services through Hosur road. Socio economically Mangammanapalya, has independent houses and walkup apartments within plot areas of less than 1200 square feet.

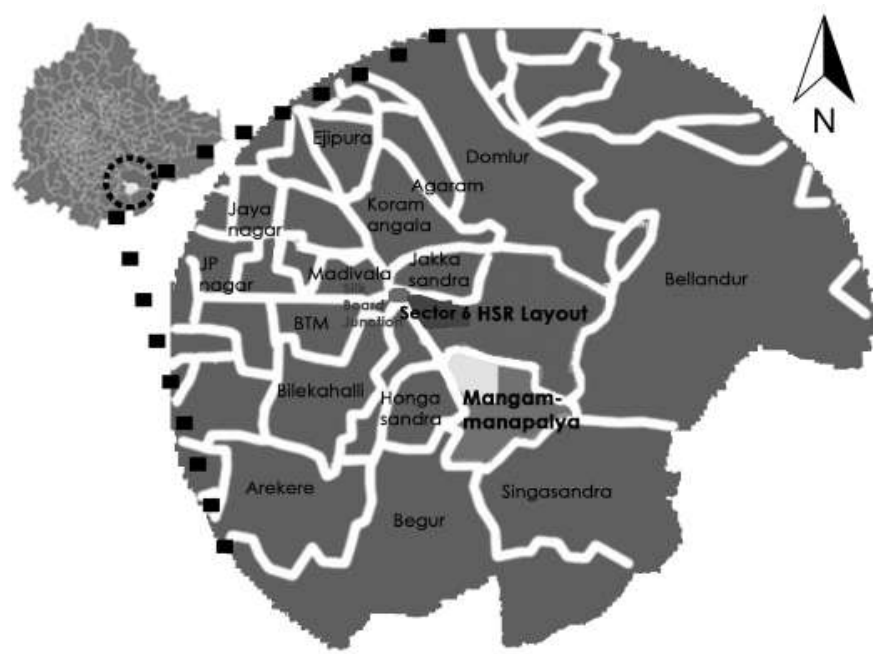

Figure 2. Inset of Bangalore map with blow up of study areas. (Source: Author)

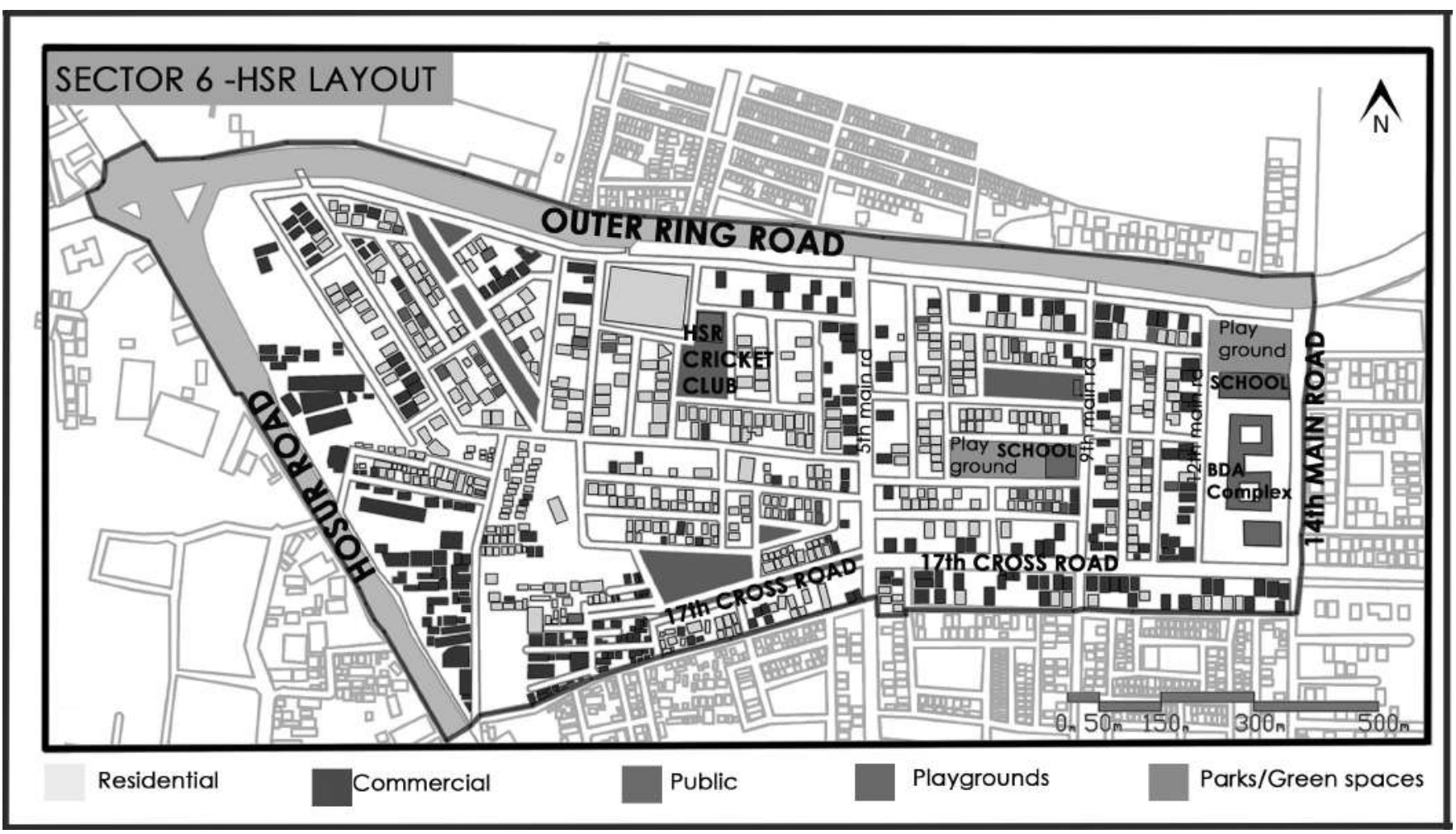

Figure 3. Land use map - HSR. (Source: Author) 


\section{Land Use and Population Density}

\subsection{Land Use and Population Density in HSR}

Land use in Sector 6 - HSR consists of a good mix of residential, commercial, public spaces and parks/playgrounds (Fig 3) with a moderate density of 8,878 persons per square kilometer. This allows a greater variety of activities to occur on a daily basis. Parks and playgrounds are available within walking distances from home. Shops and services have moderate distances and hence moderate physical exercise requires to be undertaken to reach the destinations. Among the amenities is the cricket club of HSR - a sports facility with its attached play ground. The club caters to the entire settlement and with an advantageous position in the north east corner of the layout and also caters to adjoining neighbourhoods. The parks are at an easily accessible range within the neighbourhood areas without the child having to cross heavy traffic prone roads. Playgrounds attached to schools are open to public post school hours providing the space for children to be active and thus promoting their health. This policy could be followed throughout Bangalore wherever applicable as it is a cost effective way to promote resident's health. The bulk of the neighbourhood being residential, commercial stretches in HSR are majorly found along the Outer ring road and Hosur road. Within the neighbourhood we can see commercialization happening along $17^{\text {th }}$ cross road and along the internal main roads. Though commercial units available within walking radiuses encourage independent mobility of children, fear of traffic and strangers, the two threats to children's activities are likely to increase with nonresidential land use in the neighborhood, discouraging children's outdoor activity.

\subsection{Landuse in Mangammanapalya}

Mangammanapalya a mixed use residential neighbourhood with a very high population density of 18,956 persons per square kilometer (Fig 4). Though community cohesion is very high, the land use is majorly residential. Only the fringes of the layout is commercial in the Western side along the arterial road and along the northern edge. Fabricating units are located in a random way across the layout. The longest spine in the layout is infrequently dotted with small shops. It is generally considered safe for children to visit the shops and move around. This makes for moderate trip distances for shops and services encouraging moderate physical activity. Boys are allowed to move around by themselves but girls are expected to do so with a companion or in groups. It is evident that there is a serious crunch of open spaces in this settlement. Parks are non-existent. The available ones are found a good one kilometer outside the locality. The only open space within this dense residential layout is the playground of a private school. But this playground is not open to the public post school hours. The children frequent the open space around a lake in the vicinity of the locality, usually in the evening hours to play. A few 500 meters from the lake is another playground where organized sports is conducted. A park in sector 7 of HSR layout at a distance of one kilometer is also frequented by the children on the weekends. In general, Mangammanapalya is a mixed use residential area undisturbed by any major commercial stretches or public areas providing secure areas for the child to move around within the neighbourhood.

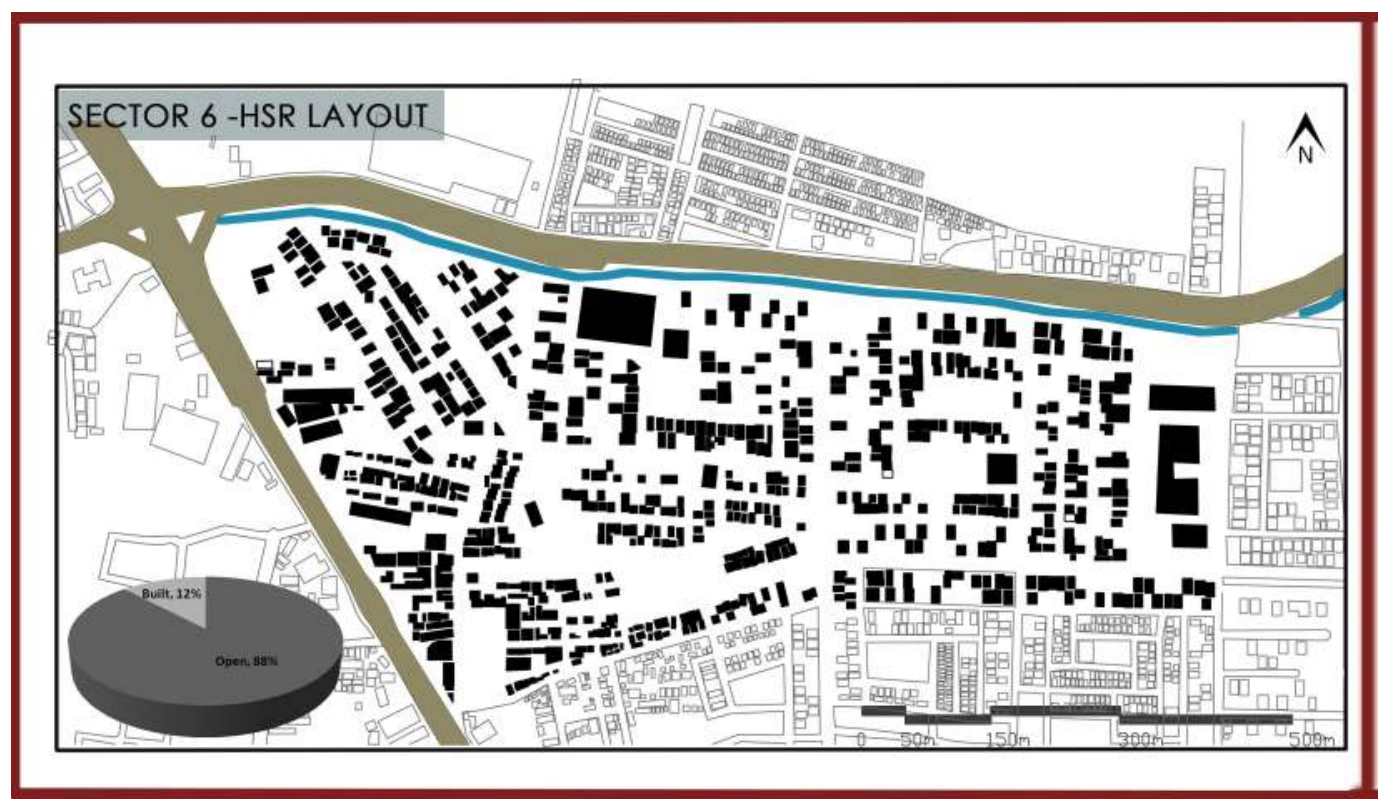

Figure 5. Figure ground map - HSR. (Source: Author) 


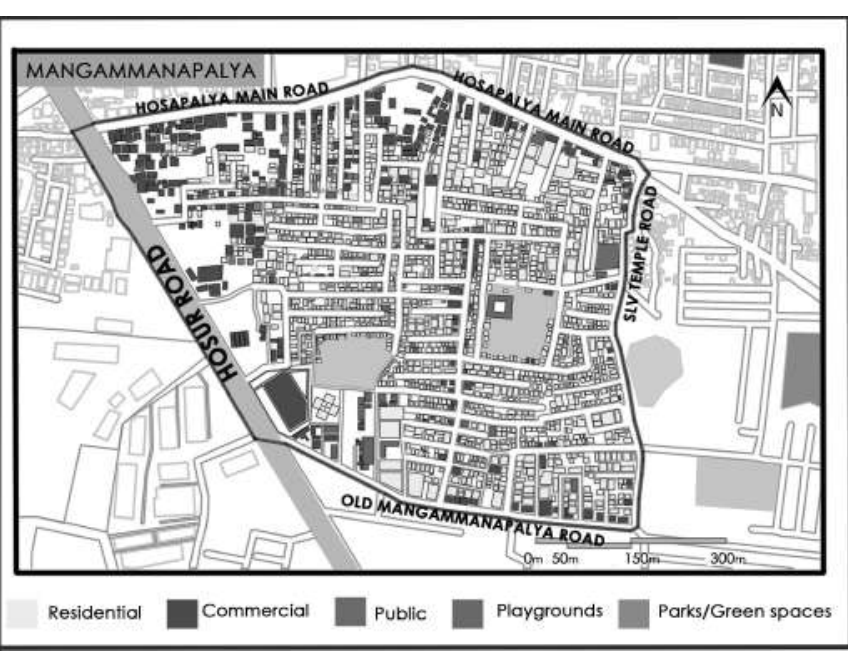

Figure 4. Land use map - Mangammanapalya. (Source: Author)

\section{Open Spaces and Typology of Open Spaces}

\subsection{Open Spaces in HSR Layout}

As a part of a planned fabric, HSR-Sector 6. Built fabric shows evenly distributed structures (Fig 5). Open space ratio to built up area is at $88: 12$. Voids between buildings imply that the neigbourhood is still growing and has not reached its maximum built potential. The available open spaces offer variety of functions. Plots are arranged in a modulated and regular way in accordance with planning byelaws. Setbacks in plots allow for immediately available play areas. It also allows for social interaction. Open spaces also increase mental well being. Open spaces are found in proximity to homes and are easily accessible. The urban fabric comes across as cellular, not very dense with coarse grain and sizeable footprints. This layout predominantly has detached independent housing with medium building heights (up to G+3). Spatial organization follows a hierarchical system. Appropriate open spaces are present contributing to physical and mental well being of children and residents.

\subsubsection{Typology of open spaces-HSR}

In HSR parks and playgrounds are distributed evenly throughout the layout (Fig 6). Other types of open spaces found are vacant plots and vacant land. Vacant plots account for almost $12 \%$ of the built environment. They are scattered all over the layout. But generally, vacant plots are either overgrown with weeds making it unsafe for children to play or fenced off, so children do not enter the plots. Children do play on those vacant plot which is free from debris and weeds in close proximity to their homes. Vacant lands on the other hand are mostly found along Hosur road. They are random in appearance and vary in terms of area. Vacant land are used for dumping of construction material and debris and are also used for parking of trucks. Children do not generally find these place conducive to play. Setbacks also provide opportunities for small bouts of play and are generally used for social interaction.

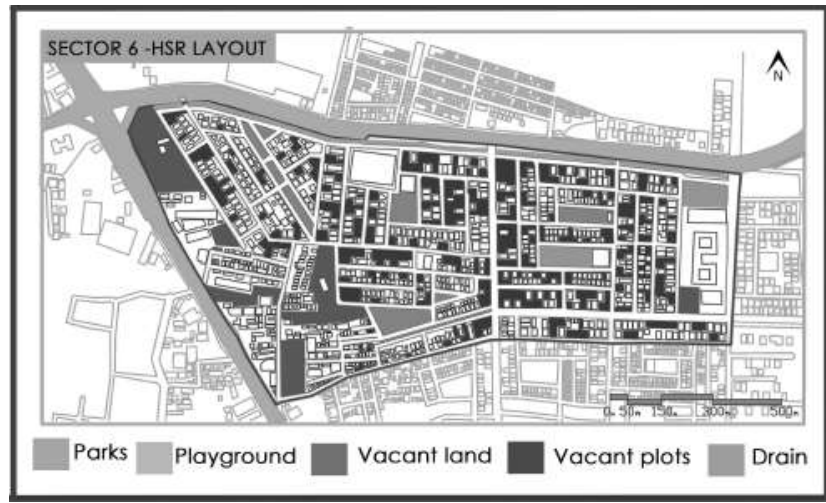

Figure 6. Typology of Open spaces - HSR. (Source: Author)

\subsection{Open Spaces in Mangammanapalya}

Development in Mangammanapalya is organic with buildings arranged in an irregular and unplanned way. Proportion of built form implies the neigbourhood is almost reaching its maximum built potential. Urban fabric comes across as cellular, very dense with fine grain and comparatively small footprints (Fig 7). Built fabric shows irregularly distributed structures. Built density is high. Ratio of open spaces is to built mass is 72:28. There is an acute lack of appropriate open and public spaces. Width of the pathways indicate pedestrian and non-motorized connections than motorized connections.

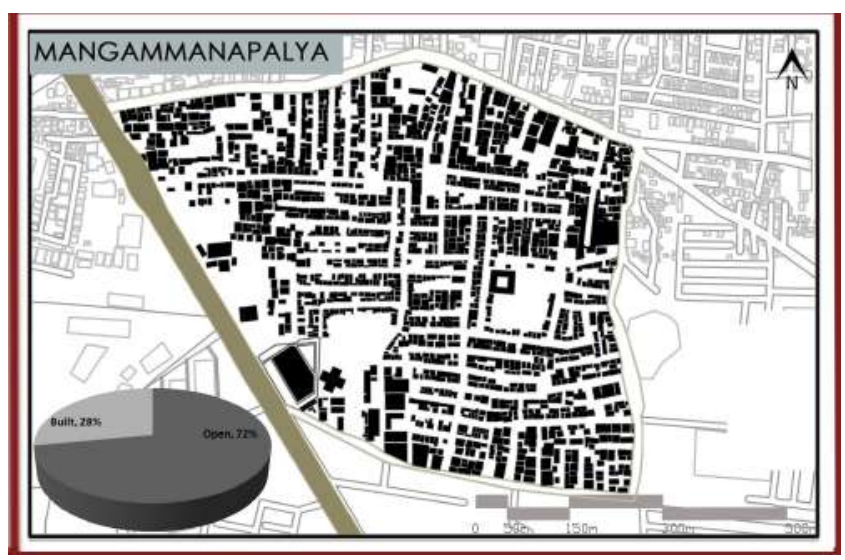

Figure 7. Figure ground map - Mangammanapalya. (Source: Author)

\subsubsection{Typology of open spaces - Mangammanapalya}

The crunch of open spaces is acutely felt within Mangammanapalya. The houses are attached on the sides and is found lacking in terms of setback spaces. The only relief is provided by the playground of the private school. 
The playground is used only by the students. The authorities as a policy could think of opening up the playground to the residents and children to provide some much needed space for physical activities. Vacant land is again found along Hosur road. The sizes of the vacant land are not constant and they are place randomly. Further they are not easily accessible by the street network because of the dead ends. They are filled with construction debris making the land unfit for children's play activities. Vacant plots not being much the street becomes the only other open space. The government could think of developing the vacant land under the authority, as parks for the children as other existing parks and playgrounds are beyond the locality (Shown in dotted circles - Fig 8) boundary in the range of one Kilometer.

\section{Territorial Space}

\subsection{Territorial Space - HSR}

HSR layout is bounded by arterial roads on the Northern and Western end which makes for a clear boundary. The $14^{\text {th }}$ Main road along with the layer of public spaces consisting of the BDA and the school make up the boundary on the eastern end. On the South the $17^{\text {th }}$ cross road - a sub arterial road acts as the boundary. Within the layout the sub arterial roads divide the neighbourhood up into 2 territories (Fig 9). These sub arterial roads act as feeder systems for the city trunk services and have moderate traffic volume with buses plying on them. These linear pathways act as boundary limits since children are sometimes not allowed to cross these roads. The planned areas make up for one kind of territory while the unplanned part denoted in blue make up for a different kind of territory. This area more or less belongs to the commercial zone found along Hosur road.

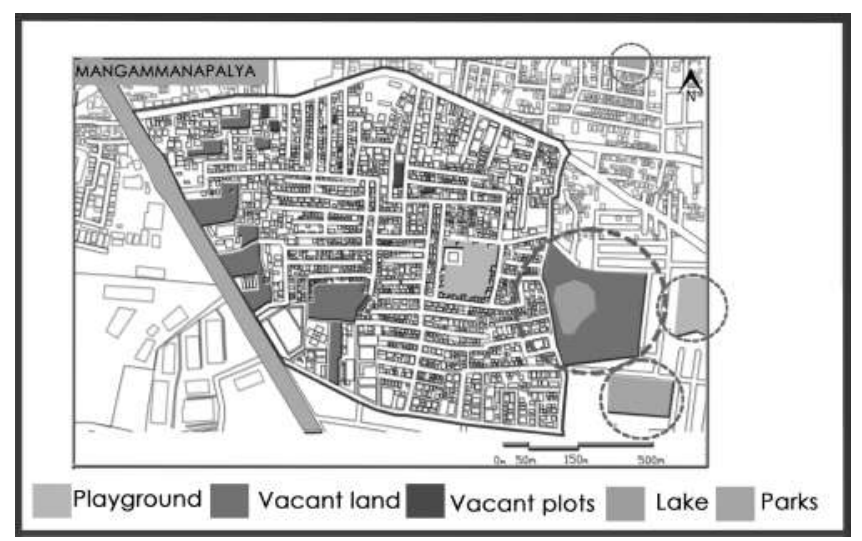

Figure 8. Typology of open spaces - Mangammanapalya. (Source: Author)

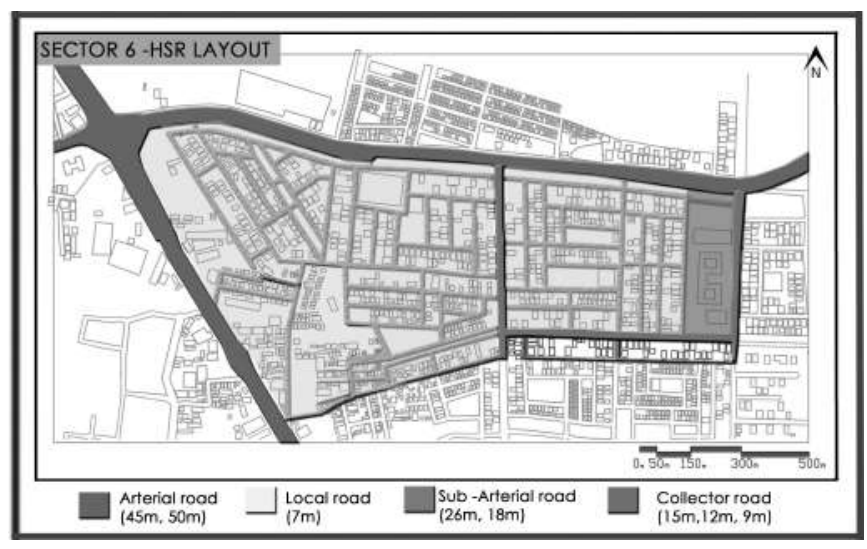

Figure 9. Territorial space - HSR. (Source: Author)

\subsection{Territorial Space - Mangammanapalya}

Mangammanapalya is more or less homogenous as it has the same density throughout. Bounded by an arterial road on the west, the boundaries on the other cardinal directions consist of only collector and local roads. The type of street that runs throughout the layout is also the same contributing to the homogeneity. Barring the area along Hosur road which is mainly for commercial purposes, the entire locality is just one territory (Fig 10). Mobility is thus spread around the whole of the locality. The mean home range is probably greater than that of HSR which means that opportunities for physical activity in terms of walkability levels are better.

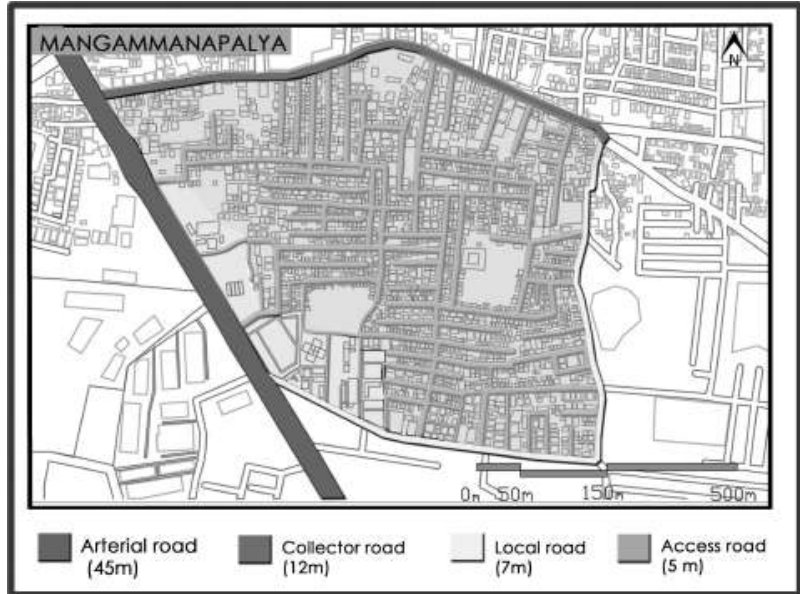

Figure 10. Territorial space - Mangammanapalya. (Source: Author)

\section{Street Network Pattern}

\subsection{Street Network Pattern - HSR}

Analyzing the street network pattern of HSR it can be seen that it contains mostly $\mathrm{T}$ junctions( Fig 11 and 
Fig 11a). T junctions depict 3 way permeability forcing vehicles to slow down and change direction or stop. With good street connectivity and slower traffic speeds use of non motorised means of travel is encouraged providing a relatively safe environment for children encouraging their independent mobility. While Mangammanapalya has less levels of permeability and connectivity, almost one-third of the streets are dead ends in this organic network (Fig 12 and Fig 12a). These streets with a width of 5 meters are mostly frequented by two and three wheelers. Since there is very little or no traffic on these streets, the perception of safety is high. Children use the entire stretch of the street for play as there is no fear of fast moving vehicles or high traffic volumes. Mostly only people who belong to the street enter the street and hence the fear of stranger danger is also averted. The only disadvantage being the circuitous route to destinations like the parks and playgrounds that are out of the locality.

\section{Survey Analysis}

A survey was conducted to know about the Children's outdoor activities and their perceptions about their neighbourhood in general. Both HSR and Mangammanapalya were divided into 5 districts each. From each district a sample of 2 numbers (children of 6yrs to 12 yrs) were selected. The sample size of each layout was 10 children. Total sample size including both the layouts were 20. As far as HSR layout was concerned, $60 \%$ of children felt that the commercialization of the main roads have led to increase of volume of traffic. Children felt the pressure of the traffic made territorial boundaries and spent most of their time within these conceived territories. $95 \%$ of the participants were in for the idea of dedicated cycle tracks and better pedestrian walkways fitted with appropriate seat furniture like seating. The socioeconomic status of the residents allowed the children to own e-gadgets like smart phones and laptops hence $58 \%$ of the children spent 0 to $1 / 2$ hour with technology and 35\% spent about half hour to one hour. $75 \%$ of the children spent half hour to one hour in outdoor activities including play and $10 \%$ spent one to two hours. Only $3 \%$ spent above 2 hrs in play and outdoor activities. In Mangammanapalya the fear of traffic was almost non-existent. So children felt safe to roam and explore everywhere in the neighbourhood. Socio economic status of the families allowed them to own only TVs and basic versions of mobile phones hence $65 \%$ of the children spent half hour to one hour in outdoor activities and $80 \%$ spent zero to half hour with the television in the evenings.

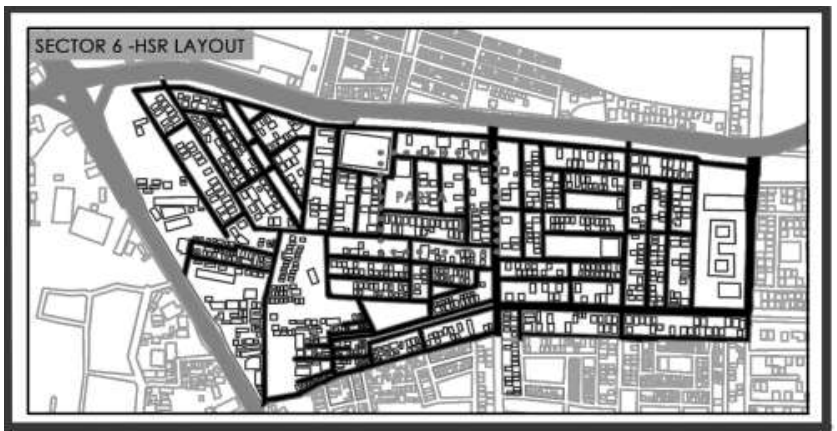

Figure 11. Street network - HSR. (Source: Author)

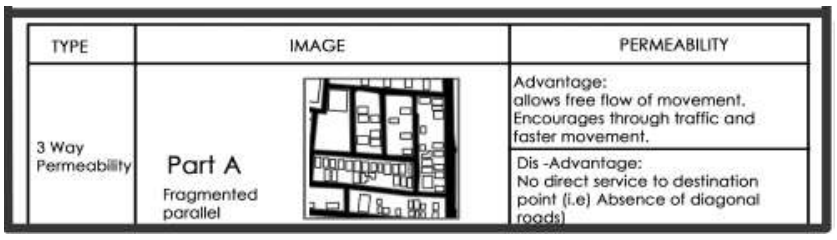

Figure 11a. Blow up of street network - HSR. (Source: Author)

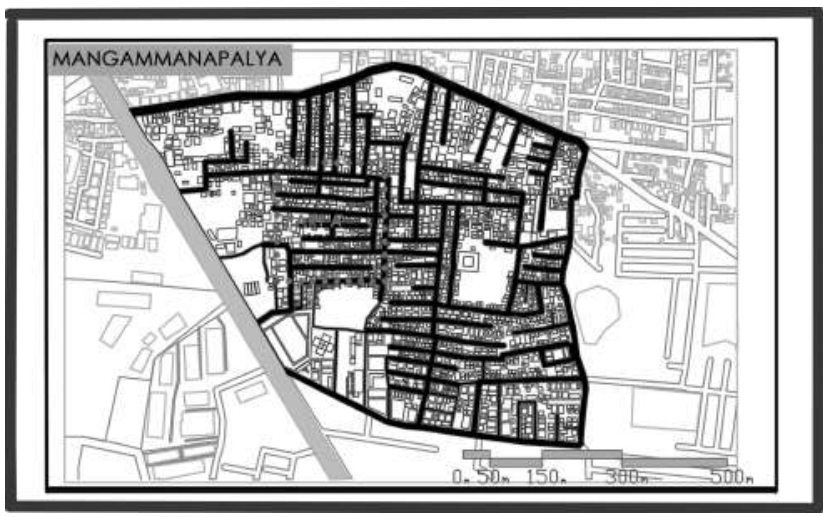

Figure 12. Street network - Mangammanapalya. (Source: Author)

\begin{tabular}{|c|c|l||}
\hline TYPE & IMAGE & \multicolumn{1}{c|}{ PERMEABILTY } \\
\hline \multirow{3}{*}{ Cul de soc } & $\begin{array}{c}\text { Part A } \\
\text { Dendritic Pattern }\end{array}$ & $\begin{array}{l}\text { Advantages: } \\
\text { Safe areas for children to play. }\end{array}$ \\
\cline { 3 - 4 } & $\begin{array}{l}\text { Dis-advantages: } \\
\text { Places significant restrictions for } \\
\text { movement of all users. } \\
\text { Discourages through vehicle } \\
\text { movement. }\end{array}$ \\
\hline
\end{tabular}

Figure 12a. Blow up of street network - Mangammanapalya. (Source: Author)

\section{Recommendation - Child friendly Routes}

A child friendly network of streets having a dynamic, pleasant and safe environment can be introduced in each neighbourhood. Pathways linking different destinations 


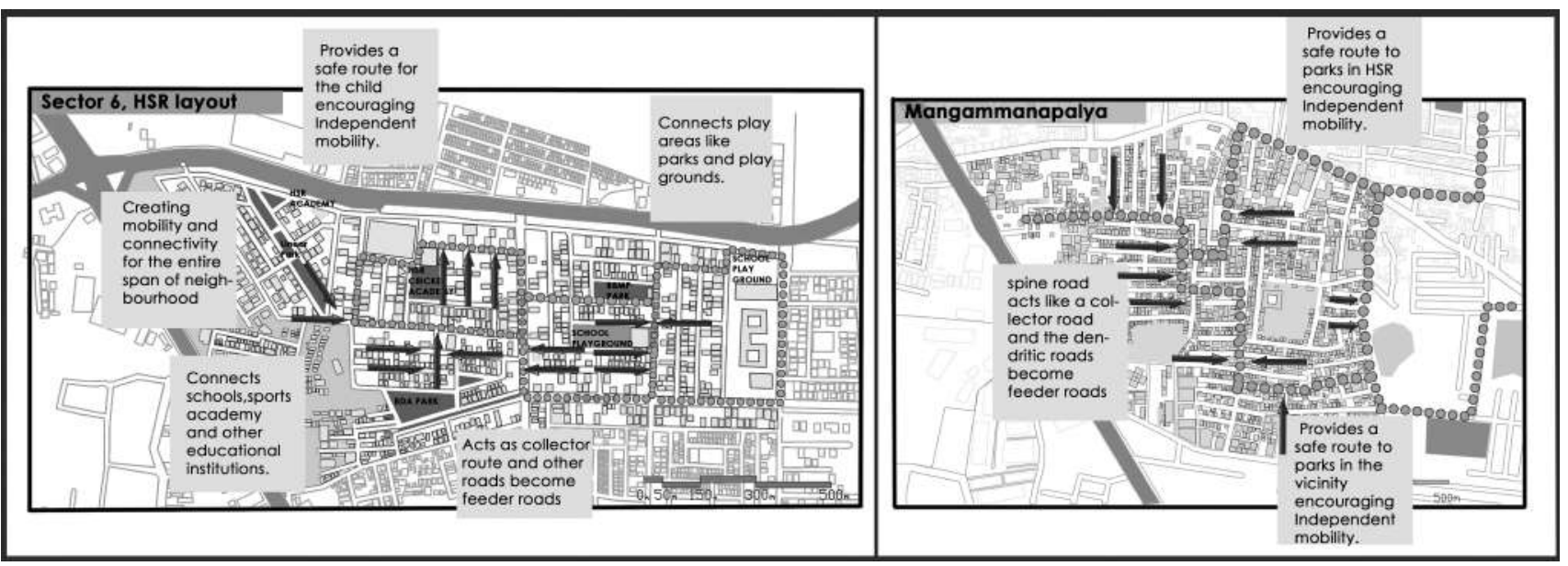

Figure 13. Suggested child friendly routes in HSR and Mangammanapalya. (Source: Author)

and areas within a neighbourhood are actively used by the children (Ward Thompson, 2013). These spaces allow the child to be themselves and maximize their opportunities for self development. These streets can link destinations like school, parks and playgrounds. The route can have its unique identity and act as the preferred path for children to travel. The child friendly route may work best when it is a loop (Fig 13). These routes can be fitted with dedicated cycling paths, play pockets, street furniture and appropriate signage. Features like pelican crossings, customized pedestrian crossings and unique paving patterns can make it look vibrant and aesthetically pleasing. Safety is of paramount importance here. To increase natural surveillance, measures like increasing the porosity of the compound wall, promoting bay windows, porches and balconies to face the street, natural access control and good lighting can be incorporated. Traffic calming techniques like woonerfs, table top crossings, active frontages and chicanes could be deployed. Streets could also be fitted with CCTVs with an alarm button which connects to the nearest control center. Overall, the child friendly route can minimize crossings and avoid complicated intersections making it a legible, direct and safe route.

\section{Technological Advancements in Play}

With the advances in technology children nowadays have home based choices like Television, video games, smart phones and laptop making them spend their free time at home instead of playing outside. This lifestyle change has brought about a decrease in the amount of physical activity normally undertaken by children. But if technology is the culprit then technology is also the provider. Through Augmented reality technology has re-engineered the outside making it more attractive for active play. By wearing specialized glasses the real world environment is augmented with superimposed computer generated images enhancing the perception of reality. The child could simply be running round in a virtual maze (The Globe and Mail, 2015) in an open area or play "Mario" along car free paths emulating new forms of play in public spaces (CNET, 2018). Augmented technology has ample scope for future research. Future neighbourhoods should be designed to synthesize with technology and should provide physical and socio-cultural environment that support healthy growth of children.

\section{Conclusion}

Urban environments provide an inadequate range of natural environment for children's activity than suburban or small town environments. The allure of opportunities for activities like jumping, playing, skipping etc that cities offer may be inhibited compared to rural environments. The study has documented the built environment variables of a planned and organic settlement in an urban fabric. Layers of physical settings have been studied. Findings revealed different settings that support physical activities of children in each type of settlement. HSR, the planned settlement, characterized by a greater number of affordances, had a greater diversity of settings and supported a variety of children's activities. Fear of traffic and stranger danger is evident in HSR while Mangammapalya, the organic settlement was high on traffic safety providing moderate affordances in terms of dead ends and narrow traffic free roads. Opportunities for providing cardiovascular activities like swimming pools, skate parks, adventure playgrounds that is required for healthy development could be looked into in HSR. Also reinforcing safety measures for traffic and stranger danger could be thought of. Mangammanapalya has no formal open spaces. But the authorities could look into the vacant land being 
converted into much needed parks and playgrounds. The findings may provide a reference framework for designing health promoting neighbourhoods in the future.

\section{References}

Brussoni, M., Olsen, L., Pike, I. and Sleet, D. (2012). Risky Play and Children's Safety: Balancing Priorities for Optimal Child Development. International Journal of Environmental Research and Public Health, 9, 3134-3148. DOI: 10.3390/ijerph9093134 Available at: https://www.sciencedirect.com/science/article/pii/ S1877042816302403?via\%3Dihub [Accessed 11 Jan. 2018].

BBMP (2018). BBMP Wards: Percentage of 0 to 6 years age group population. [image] Available at: http://www. bbmprestructuring.org

Censusindia.gov.in. (2018). [online] Available at: http:// www.censusindia.gov.in/2011-prov-results/paper2/ data_files/India2/Table_3_PR_UA_Citiees_1Lakh_ and_Above.pdf [Accessed 13 Jan. 2018].

CNET. (2018). What it's like to play Super Mario in AR, and why it matters. [online] Available at: https://www.cnet. $\mathrm{com} /$ news/what-its-like-to-play-super-mario-in-ar-andwhy-it-matters/ [Accessed 13 Jan. 2018].

data.opencity.in, (2018). [online] Available at: http:// data.opencity.in/Documents/Recent/BengaluruBDA-RMP-2031-Volume_1_Vision_Document.pdf [Accessed 9 Jan. 2018].

Esa.un.org. (2018). World Population Prospects - Population Division - United Nations. [online] Available at: https://esa.un.org/unpd/wpp/publications/Files/ WPP2017_Volume-II-Demographic-Profiles.pdf [Accessed 13 Jan. 2018].

Galson, S. (2008). Surgeon General's Perspectives: Childhood Overweight and Obesity Prevention. Public Health Reports, 123(3), 258-259. Available at: https:// www.ncbi.nlm.nih.gov/pmc/articles/PMC2289973/ [Accessed 11 Jan. 2018].

Giles-Corti, B., Wood, G., Pikora, T., Learnihan, V., Bulsara, M., Van Niel, K., Timperio, A., McCormack, G. and Villanueva, K. (2011). School site and the potential to walk to school: The impact of street connectivity and traffic exposure in school neighborhoods. Health \& Place, 17(2), 545-550. DOI: 10.1016/j.healthplace.2010.12.011. Available at: https://www.sciencedirect.com/science/article/pii/ S1353829210001899?via\%3Dihub [Accessed 12 Jan. 2018].
Hanapi, N. and Ahmad, S. (2016). A Review on Environmental Characteristic that Influence Children Physical Activities in Low Cost Housing. Procedia - Social and Behavioral Sciences, 222, 19-27. DOI: 10.1016/j.sbspro.2016.05.166. Available at: https://www.sciencedirect.com/science/article/pii/ S1877042816302403 [Accessed 13 Jan. 2018].

Islam M. Z. (2008). Children and Urban Neighborhoods: Relationships between Outdoor Activities of Children and Neighborhood Physical Characteristics in Dhaka, Bangladesh. [ebook] Raleigh, North Carolina. Available at: https://repository.lib.ncsu.edu/bitstream/ handle/1840.16/3963/etd.pdf? [Accessed 9 Jan. 2018].

Kristin, T., (2008). Neighborhood Design: Associations between Suburban Neighborhood Morphology and Children's Outdoor, Out-of-school, Physical Activities. (2008). [ebook] Raleigh, North Carolina. Available at: http://www.lib.ncsu.edu/resolver/1840.16/3220 [Accessed 9 Jan. 2018].

mospi.nic.in (2017). Ministry of Statistics and Programme Implementation - Government of India. [online] Available at: http://www.mospi.nic.in/sites/default/ files/publication_reports/Youth_in_India-2017.pdf. [Accessed 09 Jan. 2018].

Santos, M., Pizarro, A., Mota, J. and Marques, E. (2013). Parental physical activity, safety perceptions and children's independent mobility. BMC Public Health, 13(1). Available at: https://bmcpublichealth.biomedcentral. com/articles/10.1186/1471-2458-13-584 [Accessed 11 Jan. 2018].

The Globe and Mail (2015). Technology can make it safe for children to play outdoors again. [online] Available at: https://www.theglobeandmail.com/life/health-andfitness/health-advisor/technology-can-make-it-safefor-children-to-play-outdoors-again/article25967976/ [Accessed 16 Mar. 2017].

Ward Thompson, C. (2013). Activity, exercise and the planning and design of outdoor spaces. Journal of Environmental Psychology, 34, 79-96. DOI: 10.1016/j.jenvp.2013.01.003. Available at: https://www.sciencedirect.com/science/article/pii/ S0272494413000054?via\%3Dihub [Accessed 11 Jan. 2018].

Waygood, E. and Kitamura, R. (2009). Children in a Rail-Based Developed Area of Japan. Transportation Research Record: Journal of the Transportation Research Board, 2125(1), 36-43. Available at: http://journals.sagepub.com/doi/10.3141/2125-05 [Accessed 11 Jan. 2018]. 